\title{
Reinterpreted sea surface temperature proxies alter understanding of interglacial warmth
}

\author{
SAMANTHA BOVA ${ }^{1}$, YAIR ROSENTHAL ${ }^{1}$, ZHENGYU $^{2}$ \\ LIU $^{2}$, SHITAL GODAD ${ }^{1,3}$ AND MI YAN ${ }^{4,5}$ \\ ${ }^{1}$ Rutgers University \\ ${ }^{2}$ The Ohio State University \\ ${ }^{3}$ National Taiwan University \\ ${ }^{4}$ Nanjing Normal University \\ ${ }^{5}$ Pilot National Laboratory for Marine Science and Technology \\ Presenting Author: samantha.bova@rutgers.edu
}

Proxy reconstructions of global mean annual surface temperature indicate peak temperatures in the first half of the last and current interglacial periods followed by cooling ${ }^{[1-3]}$, while climate models simulate long-term warming ${ }^{[4,5]}$. Although it has been suggested that the discrepancy may be explained by seasonal biases in proxy temperature reconstructions ${ }^{[6-9]}$, this assertion has not been validated. Here we assess the effect of proxy seasonal bias by reconstructing the western Pacific warm pool SST during MIS 5e, when Earth's seasonality was maximal. We then propose a Seasonal to Annual mean Transformation (SAT) method, that enables (1) identification of seasonal bias in individual proxy records using MIS 5e SSTs and (2) removal of the seasonal component from the proxy SST record, leaving the mean annual signal in the residual.

Applying the SAT method to a suite of marine SST reconstructions, we demonstrate that two of the most common paleotemperature proxies used in interglacial temperature compilations, planktic foraminiferal $\mathrm{Mg} / \mathrm{Ca}$ and the alkenone $\mathrm{U}^{\mathrm{K}}{ }_{37}$ index, reflect seasonal rather than mean annual SSTs at a majority of core sites. In removing the seasonal component of the SST records using the SAT method, we find an absence of early interglacial warmth in the annual mean and instead find, consistent with models ${ }^{[4,5]}$, that global mean annual temperatures have been rising since the early Holocene, first in response to retreating ice sheets (12-6 ka) and then in response to rising greenhouse gas concentrations (6-0 ka). In contrast, mean annual temperatures during the LIG were relatively stable. Our study suggests that Earth's global temperatures have reached levels that have not been observed over the past 12,000 and perhaps 128,000 years.

[1] Kaufman et al. (2020) Scientific Data 7, 201. [2] Kaufman et al. (2020) Scientific Data 7, 183. [3] Marcott et al. (2013) Science 339, 1198-1201. [4] Liu et al. (2014) PNAS 111, E3501E3505 [5] Lu et al. (2019) Geophys Res 46, 9786-9795. [6] Marsicek et al. (2018), Nature 554, 92-96. [7] Rodriguez et al. (2019), Paleocean and Paleoclim 34, 1234-1245 [8] Timmermann et al. (2014) Paleocean. 29, 680-696. [9] Leduc et al. (2010) Qua Sci Rev 29, 989-1004. 